\title{
Charactor of JNK and P53 in Taxol-Induced Apoptotic Signaling in SKOV3 Human Ovarian Cancer Cell Proliferation
}

\author{
Medo Al-Inany, Mostafa A* \\ Department of General Surgery, Faculty of Medicine, Egypt.
}

*Corresponding Author : Mostafa A, Department of General Surgery, Faculty of Medicine, Egypt. Email: mostafa@gmail.com

Received date: July 30,2017;Accepted date : August 20,2017; Published date: September 04,2017.

Citation for this Article: Medo Al-Inany, Mostafa A, Charactor of JNK and P53 in Taxol-Induced Apoptotic Signaling in SKOV3 Human

Ovarian Cancer Cell Proliferation. J Cancer Research and Cellular Therapeutics, Doi: 10.31579/2640-1053/017

Copyright : (c) 2017 Mostafa A. This is an open-access article distributed under the terms of The Creative Commons Attribution License, which permits unrestricted use, distribution, and reproduction in any medium, provided the original author and source are credited.

C-Jun N-terminal kinase (JNK) represents a group of mitogenactivated protein kinases (MAPKs) involved in many cellular responses including apoptosis. We have previously reported that taxol, a microtubule-interfering therapeutic agent widely used against various cancers, induces caspase-independent but apoptotic inducing factor (AIF)-dependent apoptosis in human ovarian cancer cell line SKOV3 cells. In the present study, we add to this report a detailed analysis of the taxol-induced apoptotic mechanisms in SKOV3 cells, particularly focusing on JNK and p53. In line with the previous report, we found that taxol induced caspase-independent apoptosis with concurrent activation of JNK, phosphorylation of Bcl-2, Bax translocation to the mitochondria, and AIF release from the mitochondria. Restoration of p53 functionality into SKOV3 cells, which are p53-null cells, by transfection of wild-type p53, however, induced caspase-dependent apoptosis in response to taxol treatment as evidenced by increasing PARP cleavage and the emergence of processed, active caspase-3 and -7. More to the point, treatment with a JNK inhibitor SP600125 blocked taxol-induced apoptotic cell death in both parental SKOV3 cells (p53-deficient) and p53-transfectant cells. Collectively, the aforementioned findings lend support to the view that taxol-induced apoptotic cell death in SKOV3 cells is executed by different mechanisms depending on the presence of p53 but commonly mediated by ASK1-JNK and/or -p38 axes.

Paclitaxel or commonly called taxol is an anti-neoplastic agent specifically targeting microtubules, promoting microtubule depolymerization and thereby alters microtubule dynamics [1,2]. Such microtubule damage leads to the activation of mitotic spindle checkpoint whereby a transient arrest of the cell cycle in the mitosis may occur [2]. After mitotic arrest, cells can enter into apoptosis or exit from mitosis without dividing. The taxol-induced apoptotic signaling appears to be transmitted mainly via the mitochondriadependent pathway which involves the release of cytochrome $\mathrm{c}$ and subsequent activation of caspase 9 and 3 [3]. c-jun N-terminal kinase (JNK) activation has also been observed in cells treated with microtubule targeting agents including paclitaxel [4,5].

JNK represents a group of mitogen-activated protein kinases (MAPKs) involved in many cellular responses including apoptosis [6]. A wide range of biological outcomes have been attributed to JNK activation, including enhanced proliferation or survival, after an exposure to stress, but the majority of published evidence supports the JNK's role in conveying apoptotic signals when cells are exposed to DNA damage or anticancer therapies. A variety of JNK substrates including ATF-2, c-Jun, Bcl-2, Bcl-XL, p21Cip1/Waf1, and p53 have been identified, providing insight into the ultimate effects of activated JNK within varying cellular contexts [7]. JNK is activated by sequential phosphorylation through a MAP kinase module (MAPKKK and MAPKK).
Once activated, JNK phosphorylates and regulates the activity of transcription factors such as the AP-1 family member and c-Jun [6]. It has also been unequivocally documented that JNK is necessary and sufficient for the activation of an intrinsic cell death pathway, and that pro-apoptotic members of the Bcl-2 family, BAX or Bak, are recruited for the execution of JNK-dependent apoptosis [8].

Microtubule-interfering agents seem to activate JNK through a signal transduction involving apoptosis signal-regulating kinase-1 (ASK1) $[9,10]$. ASK1, a $160 \mathrm{kDa}$ serine/threonine protein kinase, is a member of the mitogen-activated protein kinase kinase kinase (MAPKKK) family and activates both p38 MAPK and JNK by directly phosphorylating and/or via activating SEK1 (also known as MKK4) [11-15]. The ASK1-mediated JNK activation causes the phosphorylation of Bcl-2, leading to a reduction of its anti-apoptotic activity [16]. However, the detailed molecular mechanism that links mitochondria-dependent apoptosis and ASK1p38/JNK activation remain largely unknown [17].

p53 tumor suppressor protein is a short-lived transcription factor that serves as a key player in the cellular response to a variety of extra- and intracellular insults such as DNA damage, oncogenic activation, and microtubule disruption $[18,19]$. p53 exerts its function mainly through the transcriptional activation of target genes such as CDK inhibitor and p21waf1/Cip1 for arresting the cell cycle, and the pro-apoptotic protein, Bax, for inducing apoptosis [20]. Similar to other stresses, microtubule disruption results in an increase in p53 phosphorylation at multiple sites in a drug- and cell-specific manner with a resultant accumulation of transcriptionally active proteins [21,22]. In fact, accumulating evidence suggest that $\mathrm{p} 53$ is a major mediator in DNA damage-induced apoptosis [23].

Previously, we reported a caspase-independent but AIF-dependent apoptosis in association with taxol treatment in SKOV3 human ovarian cancer cells. Extending this finding, in this study, we have demonstrated that the phosphorylation of JNK is a key molecular event in the taxolinduced apoptotic signal transduction in SKOV3 cells. Furthermore, we have also provided evidence that Bcl-2 is bound to, thus phosphorylated by activated JNK, and BAX is subsequently translocated into the mitochondria, leading to AIF release from the mitochondria. However, when p53 is restored into SKOV3 cells, the taxol-induced apoptotic signaling is shifted from a caspase-independent to a caspase-dependent signaling, raising an intriguing possibility of conferring on p53 a new role in the apoptotic cell death.

\section{Materials and Methods}

\section{Antibodies and reagents}

Paclitaxel was purchased from Sigma-Aldrich (St. Louse, MO). SP600125, a JNK inhibitor, was from Merck (Darmstadt, Germany). RPMI 1640 medium and penicillin/streptomycin solution were from Gibco $^{\circledR}$ Invitrogen (Grand Island, NY). 
Heat-inactivated fetal bovine serum (FBS) was from WelGene (Seoul, S. Korea). TransIT-LT $1{ }^{\circledR}$ was from Mirus Bio (Madison, WI). 5,5'6,6'-tetrachloro-1,1'-3,3'-tetraethylbenzimidazolyl-carbocyanine iodide (JC-1) and streptoavidin-conjugated Alexa Flour 488 dye (FITC) were from Molecular Probe (Eugene, OR). Mouse monoclonal anti-Bcl-2, anti-JNK, anti-p-JNK, rabbit polyclonal anti-AIF, anti-p-cJun antibodies were from Cell Signaling Technology (Beverly, MA). Anti-p-ERK, anti-ERK, horse radish peroxidase (HRP)-conjugated anti-mouse and anti-rabbit secondary antibodies were from Santa Cruz Biotech (Santa Cruz, CA). Biotin conjugated goat anti-rabbit and mouse secondary antibodies were from ZYMED (San Francisco, CA). Protease and phosphatase inhibitor cocktail containing PMSF, pepstain, leupeptin, and aprotinin was from Calbiochem (La Jolla, CA). Protein A/G-plus agarose ${ }^{\circledR}$ was from Santa Cruz Biotech. Polyvinylidene difluoride (PVDF) membrane was from Amersham (Piscataway NJ). Enhanced chemiluminescence reagents were from Pierce (Rockford, IL). TACS ${ }^{\text {TM }}$ MTT cell proliferation assay kit was from R\&D systems (Minneapolis, MN). Bio-Rad protein assay reagent was from Bio-Rad (Hercules, CA). Fluorescent mounting medium was from DAKO (Carpinteria, CA). Mitochondria isolation kit was from Pierce (Rockland, IL). The pCMVp53 vector that harbors the wild type p53 cDNA was from Clontech (Madison, WI). Other chemicals unless otherwise specified were from Sigma-Aldrich.

\section{Cell culture and transfection of p53}

Human ovarian SKOV3 carcinoma cells were purchased from American Tissue Culture Collection (ATCC, HTB-77) and maintained at $37^{\circ} \mathrm{C}$ in RPMI 1640 medium supplemented with $10 \%$ fatal bovine serum (FBS), 1\% L-glutamine, and $1 \%$ penicillin/streptomycin $(\mathrm{pH}$ 7.4) in a humidified atmosphere containing $5 \% \mathrm{CO}_{2}$. For transient expression of p53, SKOV3 cells were grown to about $60-70 \%$ confluency in RPMI 1640 medium supplemented with 10\% FBS, penicillin and streptomycin solution in a 24-well plate and transfected with pCMVp53 vector encoding the wild type p53 by using TransIT $^{\circledR}{ }_{-}$ LT1 transfection reagents according to the manufacturer's instructions. Cells were harvested $24 \mathrm{hr}$ after transfection prior to an experiment.

\section{Western blot analysis}

Cells grown in plastic dishes were harvested and washed with ice-cold phosphate-buffered saline (PBS). Whole-cell lysates were obtained by lysis in the lysis buffer containing $50 \mathrm{mM}$ Tris, $\mathrm{pH} 6.8,150 \mathrm{mM} \mathrm{NaCl}$, $10 \%$ SDS, $1 \%$ NP-40, $1 \%$ Triton X-100, 1 mM EGTA supplemented with a mixture of protease and phosphatase inhibitors containing 1 mM PMSF, 1 ?M pepstatin, 1 ?M leupeptin, and 0.3 ?M aprotinin. After $1 \mathrm{hr}$ incubation on ice, the lysates were centrifuged at 15,000 xg for $15 \mathrm{~min}$ at $4^{\circ} \mathrm{C}$, and the protein content in the supernatant was determined by the Bio-Rad protein assay. The sample buffer containing $60 \mathrm{mM}$ Tris- $\mathrm{HCl}, \mathrm{pH}$ 6.8, plus $2 \%$ SDS, $10 \%$ glycerol, 140 $\mathrm{mM}$ mercaptoethanol, and $0.002 \%$ bromorphenol blue was added to each whole-cell lysate, boiled for $5 \mathrm{~min}$, and resolved by the SDSpolyacrylamide gel electrophoresis (100 ?g protein/lane). Proteins resolved on the gel were electro-transferred onto PVDF membranes and immunoblotted with anti-JNK (1:1000 dilution), anti-p-JNK (1:500 dilution), anti-Bcl-2 (1:1000 dilution), anti-c-Jun (1:1000 dilution), anti-Bax (1:500 dilution), or anti-p-ASK1 (1:500 dilution) antibodies. The antibody-antigen complexes were visualized with appropriate HRP-conjugated secondary antibodies (1:5000 dilutions) and by enhanced chemiluminescence according to the manufacturer's instructions.

\section{Immuno-precipitation assay}

Cells were harvested and washed in PBS, and whole-cell lysates were prepared similarly as described above in an immuno-precipitation assay buffer consisting of $50 \mathrm{mM}$ Tris- $\mathrm{HCl}, \mathrm{pH} 7.2,0.15 \mathrm{M} \mathrm{NaCl}, 1 \%$ NP-40, 1\% deoxycholate, and 1 mM EGTA supplemented with protease and phosphatase inhibitors. Immunoprecipitation was performed by incubating the cell lysates with specific antibodies (antip-JNK) overnight at $4{ }^{\circ} \mathrm{C}$.
Immunoprecipitates were formed by the addition of protein A/G-plus agarose, collected by centrifugation, washed twice, re-suspended in the immuno-precipitation assay buffer, and subjected to the SDS-PAGE and immunoblotting with anti-p-Bcl-2 antibodies.

\section{Determination of cell viability}

Cell viability was measured by the MTT assay. Briefly, about $5 \times 103$ cells/well in 96 well plates were seeded and incubated in a humidified atmosphere containing $5 \% \mathrm{CO}_{2}$ overnight. After the culture medium was removed, $50 \mathrm{ml}$ of $0.2 \mathrm{mg} / \mathrm{ml} \mathrm{MTT} \mathrm{(3-(4,5-dimethylthiazol-2-yl)-2,5-}$ diphenyltetrazolium bromide) solution was added to each well, and the mixtures were further incubated at $37^{\circ} \mathrm{C}$ for $4 \mathrm{hr}$. The reaction was stopped by replacing the MTT solution with DMSO. Formazan released from the cells was measured by a microplate reader (Bio-Rad model 550) at $570 \mathrm{~nm}$.

\section{Immunofluorescence microscopic localization of p-JNK}

Cells grown on glass cover slips were washed with PBS, fixed with $4 \%$ paraformaldehyde in PBS at room temperature for $1 \mathrm{hr}$, and permeabilized with $0.3 \%$ triton X-100 at room temperature for 30 min before incubation with rabbit anti-p-JNK at $0.5 \mathrm{gg} / \mathrm{ml}$ for $12 \mathrm{hr}$ at $4^{\circ} \mathrm{C}$. After washing three times with PBS, cells were incubated with Alexa Fluor 488-conjugated secondary antibodies at $2 \mathrm{~g} / \mathrm{ml}$ for $4 \mathrm{hr}$ at $4^{\circ} \mathrm{C}$. Cells were washed three times with PBS, mounted with the fluorescent mounting medium, and observed under the Zeiss Axioskop 2 microscope (Carl Ziess, Oberkochen, Germany).

\section{Mitochondria isolation}

Cells were harvested in trypsin-EDTA solution and centrifuged at $850 \mathrm{xg}$ for $2 \mathrm{~min}$. The resulting cell pellets were resuspended in the same solution at about $2 \times 107$ cells/resuspension, and mitochondria were isolated by using the mitochondria isolation kit according to the manufacturer's protocol. For analysis by Western blotting, isolated mitochondria were lysed with $60 \mathrm{ml}$ of the mitochondria lysis buffer $(50 \mathrm{mM}$ Tris-HCl, $\mathrm{pH}$ $7.0,150 \mathrm{mM} \mathrm{NaCl}, 1 \% \mathrm{NP}-40,0.25 \%$ sodium deoxycholate, $1 \mathrm{mM}$ EGTA) supplemented with protease and phosphatase inhibitors.

\section{Detection of the mitochondrial membrane potential}

The mitochondrial membrane potential was analyzed using JC-1, a lipophilic cationic fluorescent dye capable of selectively entering mitochondria and acting as a dual emission probe that reversibly changes color from green to orange as the mitochondrial membrane becomes more polarized [24]. Cells at $1 \times 106 / \mathrm{ml}$ were incubated with JC-1 at $5 \mathrm{mg} / \mathrm{ml}$ for $30 \mathrm{~min}$ at $37^{\circ} \mathrm{C}$ in darkness, washed with PBS three times, and analyzed by fluorescence microscopy.

\section{Statistical analysis}

One-way ANOVA was utilized for the statistical analysis of experimental results by using the SPSS 10.0 software. $P<0.05$ was taken as significance.

\section{Results}

\section{Activation of JNK by taxol}

Despite various therapeutic outcomes of taxol in different types of cancer, less is known about the signaling pathways whereby taxol conveys its cytotoxic and apoptotic effects on cancer cells. JNK activation in response to chemotherapy treatment has been suggested to correspond to cell sensitivity to chemotherapy [25]. To this regard, we sought to test if taxol activated JNK-mediated signaling pathways, characteristically including JNK and c-Jun in SKOV3 cells. JNK activity was assessed by immunoblotting with phospho-specific anti-p-JNK1 antibodies recognizing major phosphorylation sites on Thr-183 and Tyr-185. First, we examined the time course of JNK1 activation following taxol treatment. SKOV3 cells were treated with $100 \mathrm{nM}$ paclitaxel for varying amounts of time $(0-24 \mathrm{hrs})$, and cellular levels of p-JNK1 and its substrate p-c-Jun were measured by immunoblotting. As illustrated in Figure 1, the phosphorylation of JNK1 and c-Jun were time-dependent. 
The phosphorylation of JNK1 was stimulated by taxol treatment, appearing as early as at $1 \mathrm{hr}$ after taxol treatment and steadily increasing with a maximum activation observed at $8 \mathrm{hr}$, and then declining to the basal level at $24 \mathrm{hrs}$ following drug treatment. Consistent with this observation, the emergence of p-c-Jun, a substrate of active JNK, lagged behind that of p-JNK1, reaching the peak at 12 $\mathrm{hr}$ before declining. On the other hand, unlike a recent documentation that taxol may induce a transient ERK activation [26], paclitaxel at 100 $\mathrm{nM}$ did not influence ERK activation in SKOV3 cells as evidenced by little changes in phospho-ERK1/2 immunoreactivity over the $24 \mathrm{hr}$ period, strongly suggesting that the ERK-mediated MAP kinase pathway is not activated by taxol .

A

Time (h)

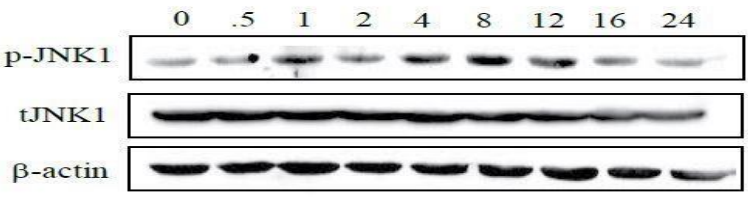

Time (h)

B

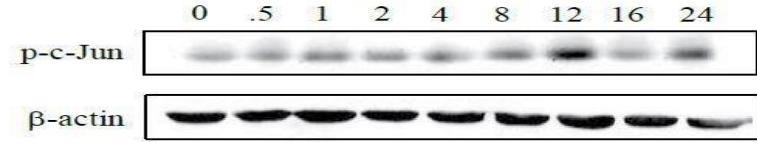

C

Time (h)

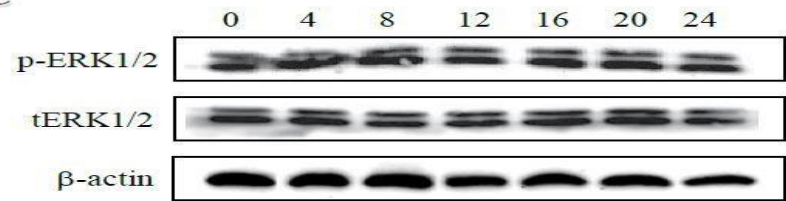

Figure 1: Immunoblotting analyses of p-JNK1, p-c-Jun and p-ERK1/2 following paclitaxel treatment of SKOV3 cells. After SKOV3 cells were exposed to $100 \mathrm{nM}$ of paclitaxel for $0-24 \mathrm{hrs}$, whole cell lysates were subjected to immunoblotting analysis for p-JNK1, p-c-Jun, p-ERK1/2, total JNK1, and total ERK probed with respective antibodies. ?-actin was used as a loading control. (A) The time course of the phosphorylation of JNK1 following taxol treatment. (B)The time course of the phosphorylation of c-Jun following taxol treatment. (C) The time course of phosphorylated ERK1/2 following taxol treatment. p-JNK1, phosphorylated JNK1; tJNK1, total JNK1; p-c-Jun, phosphorylated c-Jun, p-ERK1/2, phosphorylated ERK1/2; tERK1/2, total ERK1/2.

\section{SP600125 suppresses apoptotic cell death in SKOV3 cells}

To further ensure that the taxol-induced JNK activation is associated with apoptotic cell death in SKOV3 cells, we used a JNK inhibitor, SP600125, to see if its treatment deterred the taxol-induced cell death. Photomicrographs in Figure 2a show morphologies of apoptotic cells following paclitaxel and/or SP600125 treatment. Exposure to $100 \mathrm{nM}$ paclitaxel for $24 \mathrm{hrs}$ clearly induced cell death as evidenced by the emergence of round-shaped and buoyant cells seen in Figure $2 a(D)$, which was almost completely inhibited by co-treatment of $25 \mathrm{mM}$ SP600125 (Figure 2a(C)). We then restored the wild-type p53 into SKOV3 cells, which are p53-null, and examined if p53 alleviated the taxol-induced cell death. Contrary to our expectation, the introduction of p53 did not alleviate the taxol-induced cell death nor inhibit SP600125 ability to deter the taxol-induced cell death (Figure 2a(E)(G)). These results were further confirmed by measuring JNK activity under parallel conditions. Immunoblotting analyses showed that SP600125 affected the phosphorylation of JNK and c-Jun but in an opposite direction. The phosphorylation of c-Jun was barely detectable in the presence of $25 \mathrm{mM}$ SP600125 while that of p-JNK1 was not significantly affected by SP600125 at the same concentration up to 8 hr treatment (Figure 2b). Seen in Figure 2(c) are the extents of apoptotic cell death caused by taxol in the presence of SP600125 under different physiological contexts in terms of p53 as quantified by MTT.
$100 \mathrm{nM}$ taxol treatment increased cell death substantially in comparison with control $(p<0.05)$, which were apparently reversed almost to the control level by $25 \mathrm{mM}$ SP600125 co-treatment. A similar trend was observed with p53-transfected SKOV3 cells (SKOV3/p53 cells), suggesting that p53 may not antagonize cell death caused by taxol but rather may sensitize the taxol-induced cell death, raising a possibility that p53 activation may represent an active involvement in executing the taxolinduced cell death.
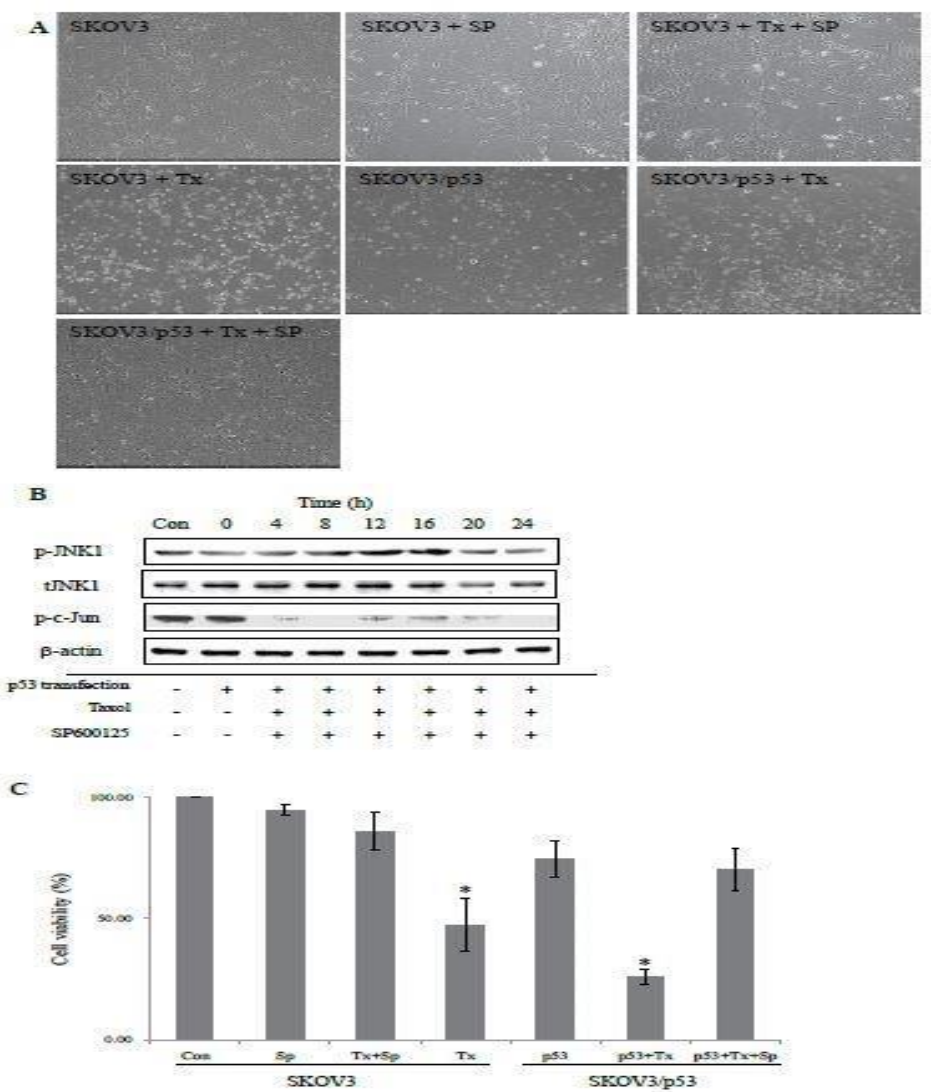

Figure 2: Effects of SP600125 on the taxol-induced apoptotic cell death of SKOV3 cells. (A) Parental SKOV3 cells and p53-transfectant SKOV3 cells (SKOV3/p53 cells) were treated with $100 \mathrm{nM}$ paclitaxel and/or $25 \mathrm{mM}$ SP600125 for $24 \mathrm{hrs}$ and viewed under a light microscope. SKOV3, SKOV3 cells without treatment; SKOV3 + SP, SKOV3 cells treated with SP600125; SKOV3 + Tx + SP, SKOV3 cells co-treated with paclitaxel and SP600125; SKOV3 + Tx, SKOV3 cells treated with paclitaxel; SKOV3/p53, SKOV3/p53 cells without treatment; SKOV3/p53 + Tx, SKOV3/p53 cells treated with paclitaxel; SKOV3/p53 + Tx + SP, SKOV3/p53 cells treated with paclitaxel and SP600125. (B) SKOV3 cells and SKOV3/p53 cells were treated with 100 $\mathrm{nM}$ paclitaxel and $25 \mathrm{mM}$ SP600125 for the indicated durations and subjected to immunoblotting analysis to examine the phosphorylation status of JNK1 and c-Jun. ?-actin was used as a loading control. p-JNK1, phosphorylated JNK1; tJNK1, total JNK1; p-c-Jun, phosphorylated c-Jun. (C) SKOV3 cells and SKOV3/p53 cells were treated with paclitaxel and SP600125 as described in (A), and cell viability was quantified by MTT assay. Data are presented as means $\pm \mathrm{SD}$ for at least five different experiments. Con, no treatment; $\mathrm{Sp}$, SP600125 treatment; Tx+Sp, paclitaxel and SP600125 co-treatment; Tx, paclitaxel treatment. *Significantly different from the corresponding control by one-way ANOVA $(p<0.05)$.

Based on previous documentation that the p-JNK-mediated apoptosis depends on the recruitment and activation of Bcl-2 [16,29], we next measured the binding of $\mathrm{p}-\mathrm{JNK} 1$ with $\mathrm{p}-\mathrm{Bcl}-2$ by the immunoprecipitation assay. Whole-cell lysates were prepared from cells that were pretreated with $100 \mathrm{nM}$ paclitaxel and/or $25 \mathrm{mM} \mathrm{SP600125}$ for 0-24 hrs and subjected to immunoprecipitation by antibodies recognizing p-JNK1. The resulting precipitates were then immunoblotted with anti-p-Bcl-2 antibodies. Taxol increased the amount of p-Bcl-2 co-precipitated with $\mathrm{p}$ JNK1 in a time-dependent manner, which remained up-regulated for up to 24 hrs but was abrogated by SP600125 co-treatment (Figure 3b). 
Proapoptotic Bax is suggested to normally exist in the cytoplasm [30,31], and ample evidence suggests that Bax has both active and inactive conformations that principally determine its subcellular distribution [32]. In response to apoptotic stimuli, Bax changes its subcellular localization and dimerization pattern in such a way that homo-dimerized Bax is transformed into a membrane-bound form and thus translocated to the mitochondria, leading to the initiation of mitochondria-dependent apoptosis [33-35]. To determine whether taxol increase Bax translocation onto the mitochondria, the mitochondria were isolated and then analyzed by immunoblotting analysis with antibodies recognizing Bax. Taxol increased mitochondrial Bax in a time-dependent manner, which was also subjected to attenuation by SP600125 treatment while cytoplasmic Bax remained unchanged following drug treatments (Figure 3c).

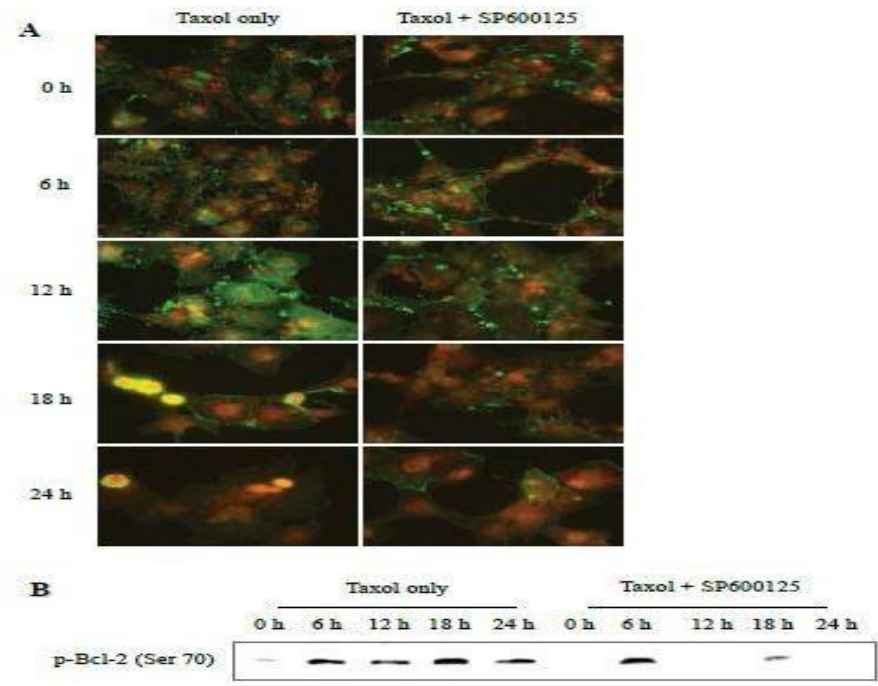

C

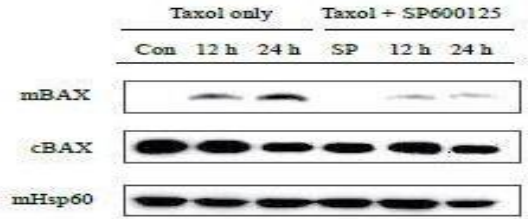

Figure 3: $\mathrm{Bcl}-2$ on the mitochondria is targeted and phosphorylated by active JNK. (A) SKOV3 cells were treated with $100 \mathrm{nM}$ of paclitaxel and/or $25 \mathrm{mM}$ of SP600125 for 0-24 hrs, subjected to a double fluorescence staining with a mitochondrial marker MitoTrackerTM (red fluorescence) and antibodies against p-JNK1 conjugated with Alexa 488TM dye (green fluorescence), and viewed under a fluorescence microscope. (B) SKOV3 cells were treated similarly to the regimen in (a), and cellular lysates were subjected to immunoprecipitation with anti-pJNK1 monoclonal antibodies, followed by immunoblotting with anti-pBcl-2 antibody. (C) SKOV3 cells were treated similarly to the treatment regimen in (a). Their mitochondria were isolated as described in materials and methods, and mitochondrial lysates were subjected to immunoblot analysis for BAX. mBAX, mitochondrial BAX; cBAX, cytosolic BAX; mHsp60, mitochondrial heat shock protein 60 , which was served as a loading control.

\section{SP600125 attenuates the taxol-induced mitochondrial depolarization and AIF release}

JC-1 is a dual fluorescent membrane potential-sensitive dye that fluoresces at $590 \mathrm{~nm}$ (red fluorescence) in mitochondrial hypolarization and at $510 \mathrm{~nm}$ (green fluorescence) in mitochondrial depolarization (loss of mitochondrial transmembrane potential Dym). Mitochondrial depolarization is known to indicate an early event of apoptosis, which leads to increased mitochondrial membrane permeability and release of proapoptotic factors such as AIF into the cytosol [36]. We investigated whether Dym loss occurred following taxol treatment in a SP600125-sensitive manner.
As illustrated in Figure 4a, treatment with taxol induced mitochondrial depolarization as evidenced by higher green fluorescence than untreated cells, and this transition was clearly attenuated by SP600125 co-treatment. Also demonstrated in Figure 4, that the taxol-induced release of AIF from the mitochondria into the nucleus was greatly attenuated by the addition of SP600125 (Figure 4b).
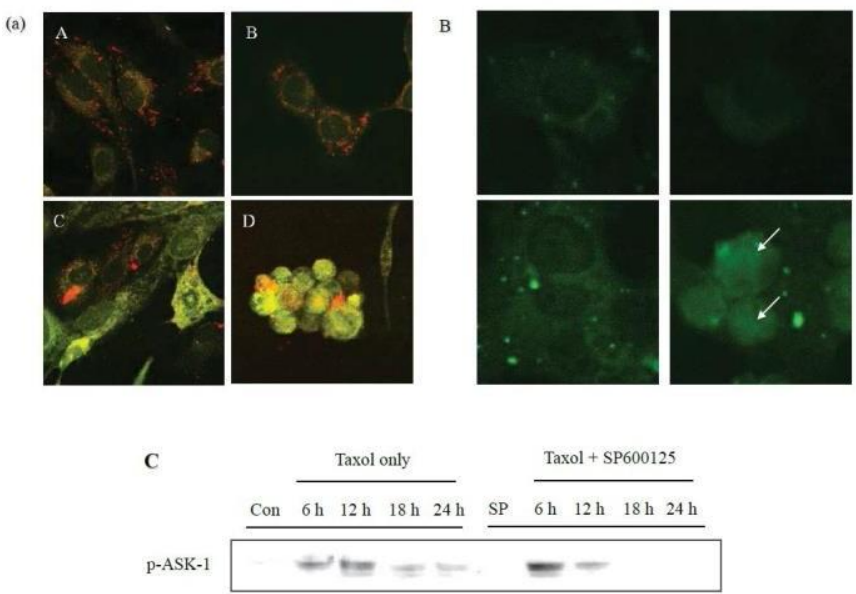

Figure 4: Effects of SP600125 on mitochondrial transmembrane potential $(\mathrm{Dy})$ and AIF release from the mitochondria.

(A) Paclitaxel and/or SP600125-treated SKOV3 cells were further incubated with $5 \mathrm{mg} / \mathrm{ml} \mathrm{JC}-1$ for $30 \mathrm{~min}$ at $37^{\circ} \mathrm{C}$ as described in materials and methods, and Dym was observed microscopically with the ZEISS Axioskop 2 microscope. A, untreated cells; B, cells treated with $25 \mathrm{mM}$ SP600125 only; C, cells co-treated with $100 \mathrm{nM}$ paclitaxel and $25 \mathrm{mM}$ SP600125; D, cells treated with $100 \mathrm{nM}$ of paclitaxel only. (B) Paclitaxel and/or SP600125-treated SKOV3 cells were fixed with 5\% formaldehyde and incubated sequentially, first, with anti-AIF antibodies for $24 \mathrm{hrs}$ at $4^{\circ} \mathrm{C}$ and then with FITC-conjugated secondary antibodies for $1 \mathrm{hr}$ at room temperature before observed by a fluorescence microscope. A, untreated cells; B, cells treated with $25 \mathrm{mM}$ SP600125 only; C, cells treated with $100 \mathrm{nM}$ taxol and $25 \mathrm{mM}$ SP600125; D, cells treated with $100 \mathrm{nM}$ paclitaxel only. The arrows in (D) point to the nucleus. (C) SKOV3 cells were incubated with $100 \mathrm{nM}$ paclitaxel and/or $25 \mathrm{mM}$ SP600125 for the indicated amount of times, collected by centrifugation, and lysed. The cell lysates were subjected to Western blotting analysis probed with anti-pASK1 antibodies.

To explore an upstream regulator of JNK activity, which might account for the early response to taxol treatment, we examined the phosphorylation status of ASK1 following taxol treatment. Figure 4(c) shows that phosphorylated ASK1 began to appear at as early as $6 \mathrm{hrs}$ and reached the peak at $12 \mathrm{hrs}$ following taxol treatment. However, unlike p-JNK1 and pc-Jun, SP600125 was not likely to attenuate the phosphorylation of ASK1, strongly implying that ASK1 may be an upstream regulator of JNK1, at least, in the taxol-induced apoptotic signaling pathway in SKOV3 cells.

Caspase-dependent apoptosis is induced when p53 is restored in SKOV3 cells

It has been well established either loss of wild type p53 function, gain of oncogenic function, or the ability to activate p53 inappropriately severely compromises the capacity for controlled cellular proliferation and growth [37]. In addition, despite the fact that both p53 and JNK have previously been shown to mediate cellular responses to the actions of a microtubuleinterfering agent [10], their interrelationships have been far from clear. To gain further insight into the mechanism regulating the p53-mediated JNK activation, wild-type p53 was reintroduced by transfection into SKOV3 cells, which are deficient of endogenous p53. Then, we characterized the taxol-induced apoptotic signaling in SKOV3/p53 cells. First, the expression level of p53 was measured by immunoblotting. As shown in Figure 5a, the expression level of p53 was significantly elevated compared to parental cells (control), and in addition, p53 expression level was not susceptible to either taxol and/or SP500125 treatment. 
The presence of cleaved poly-ADP-ribose polymerase (PARP) is one of the most frequently used diagnostic tools for the detection of caspase-dependent apoptosis in many cell types. The cleavage of PARP into two fragments of 89 and $24 \mathrm{kDa}$ has been considered indicative of functional caspase activation [38]. Figure $5 \mathrm{~b}$ revealed an increase in cleaved forms of PARP when SKOV3 cells were exposed to taxol. In addition, the induction of cleaved PARP by taxol was further augmented in SKOV3/p53 cells, implying that the induction of caspase-dependent apoptosis is p53-dependent. Intriguingly, this induction was attenuated by SP500125 treatment. More consistently, the emergence of processed thus active caspase-3 and -7 was also induced by $100 \mathrm{nM}$ taxol treatment when wild type p53 was restored in SKOV3 cells in a SP600125-sensitive manner. These data clearly suggest that p53 may play a pivotal role in the activation of caspase- 3 and -7 and the induction of caspase-dependent apoptotic cell death in SKOV 3 cells in response to taxol.

A

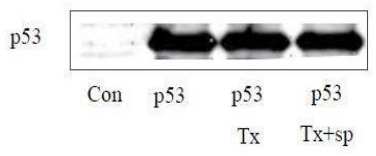

B

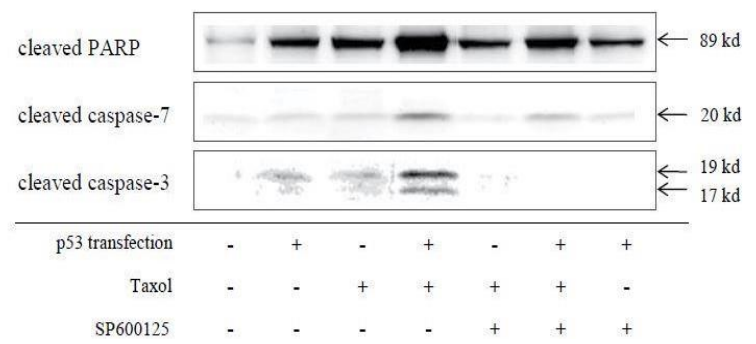

Figure 5: Apoptotic signaling induced by restoration of p53 in SKOV3 cells. (A) SKOV3 cells were transiently transfected with an expression vector encoding the wild type p53 as described in materials and methods, and the expression level of p53 was detected by Western blotting. Con, parental SKOV3 cells; p53, SKOV3/p53; Tx, paclitaxel treatment; Tx + Sp, paclitaxel and SP60015 co-treatment. (b) The SKOV3/p53 cells were treated with $100 \mathrm{nM}$ paclitaxel and/or $25 \mathrm{mM}$ SP60015 for $24 \mathrm{hrs}$ and subsequently subjected to immunoblotting for the presence of cleaved PARP and processed, active caspase- 3 and -7 .

\section{Discussion}

In the present study, we have provided evidence that supports the involvement of JNK in the taxol-induced apoptotic cell death in SKOV3 cells. The emerging view from the present studies is that apoptotic cell death is executed via the following signaling pathway in SKOV3 cells in response to taxol treatment: Taxol induces the activation of ASK1, which, in turn, increases the phosphorylation of JNK. Activated JNK binds to and thus activates mitochondrial Bcl-2 concomitant with mitochondrial Bax translocation. Translocated Bax may cause mitochondrial depolarization, which facilitates the release of AIF from the mitochondria into the nucleus. AIF in the nucleus eventually leads to apoptotic cell death via a process, generally termed 'caspase-independent apoptosis' as suggested elsewhere [36]. Further supporting our reasoning is the finding that treatment of SKOV3 cells with SP600125, a JNK inhibitor, attenuates apoptotic cell death with concurrent inhibition of signaling events that must occur downstream of JNK, such as Bcl-2 phosphorylation, mitochondrial Bax translocation, mitochondrial depolarization, and mitochondrial AIF release. Additionally, the restoration of p53 in SKOV3 cells can restore 'caspase-dependent apoptotic cell death' as evidenced by the emergence of cleaved form of PARP and caspase- 3 and -7 activation upon receiving taxol treatment. We interpret this to mean that SKOV3 cells may activate two different apoptotic signaling pathways in response to microtubule-interfering agents, e.g., taxol: caspaseindependent and caspase-dependent signaling pathway depending on the presence of p53.
Therefore, p53 may play a switchboard role in the taxol-induced apoptotic cell death in such a way that without p53, like parental SKOV3 cells, caspase-independent but mitochondria-dependent apoptotic signaling is prevalent while the introduction of p53 causes a signaling shift to caspasedependent apoptosis. Furthermore, the finding that SP60012 is effective in blocking cell deaths in both p53-null and p53-containing SKOV3 cells raises a possibility that $\mathrm{JNK}$ may be a key molecule in both caspaseindependent and caspase-dependent apoptotic signaling pathways in SKOV3 cells. Of note, recent documentation suggests

Since biochemical studies led to the identification and purification of JNK as a 'p54 microtubule-associated protein kinase' [39], JNK was found to bind the NH2-terminal activation domain of c-Jun [40,41] and thus phosphorylate c-Jun on ser-63 and ser-73 [42]. JNK is activated by treatment of cells with cytokines (e.g., TNF and IL-1) and by exposure of cells to many forms of environmental stress (e.g., osmotic stress, redox stress, and radiation) [43]. Several MAPKKK have been reported to activate the JNK signaling pathway, including members of the apoptosis signal-regulating kinase (ASK) group. Apoptosis signal-regulating kinase1 (ASK1) is characterized as a MAPK kinase kinase. Overexpression of ASK1 induces apoptosis in mink lung epithelial cells, and ASK1 is activated in cells treated with tumor necrosis factor-?, suggesting a role of ASK1 in stress-, cytokine-, and microtubule-interfering agents (MIAs)induced apoptosis $[9,44]$. However, the exact mechanism whereby JNK is activated in the stress-response is unclear. Alternatively, JNK activation may represent a protective response that is initiated by an exposure to stress. In fact, the JNK pathway has been implicated in both apoptosis and survival signaling [43]. On the other hand, JNK activation has been reported to induce cytochrome c release [45], but the mechanism is unclear. Potential targets of JNK that may regulate cytochrome c release may include members of $\mathrm{Bcl}-2$ group of apoptotic regulatory proteins [16]. Phosphorylation of Bcl-2 and/or Bcl-XL inhibits the anti-apoptotic function of these proteins. However, there are some problems with this potential mechanism. First, one study indicates that Bcl-2 phosphorylation on the same sites may be anti-apoptotic rather than pro-apoptotic [46]. The second problem is that other stimuli cause a marked Bcl-2 phosphorylation without activating JNK. Finally, the other apoptotic mechanism is independent of Bcl-2 phosphorylation and caspase activation. This reasoning may demonstrate that anti-apoptotic proteins Bcl-2 and Bcl-XL is not physiological substrates of JNK, and rather, JNK could be targeted to $\mathrm{Bcl}-2$ or Bcl-XL under specialized circumstances in the presence of an adaptor molecule that mediates the interaction. Although it is established that JNK contributes to some apoptotic response, it is not clear that apoptosis represents the only functional consequence of JNK activation and indeed JNK-dependent apoptotic signaling pathway can be blocked by activation of survival signaling pathways [47], including NF-?B, Akt/PKB and ERK.

Similarly, a significant question that remains unanswered concerns the molecular mechanism that can account for the function of JNK in apoptotic signal transduction in response to taxol. Our present data shows that taxol is not implicated in ERK phosphorylation. Indeed, our previous reports have shown that paclitaxel and selenium compounds both caused apoptosis in SKOV3 through a caspase-independent pathway [36,48]. JNK activation has been reported to induce $\mathrm{Bcl}-2$ phosphorylation $[2,16]$. Likewise, our data provide evidence that JNK signaling pathway directly regulates the apoptotic mechanism in a mitochondria-mediated fashion and activated JNK is directly responsible for the phosphorylation of Bcl-2 and Bax translocation onto the mitochondria. These findings are consistent with previous results of Nechushtan et al. [33], who clearly demonstrated in electron microscopy that Bax translocation to the outer mitochondrial membrane was the first step in Bax activation, and that the mitochondriaassociated $\mathrm{Bax}$ oligomer was the biologically active pro-apoptotic structure. The acquisition of a membrane embedded conformation, which is associated with oligomerization of Bax, facilitates the release of mitochondrial proteins such as cytochorme $\mathrm{c}$ or AIF [32].

Other potential targets of pro-apoptotic signaling activated by JNK could be tumor suppressor protein p53. When JNK is activated in cells exposed to stress, JNK phosphorylates p53, thereby inhibiting ubiquitin-mediated degradation, and stabilizing p53 protein [49]. 
However, many other studies also pointed out that although JNK may contribute to the regulation of p53 stability, p53 does not appear to be required for JNK-induced apoptosis [50]. Our findings strongly suggest the involvement of p53 in apoptotic cell death in response to taxol treatment. Moreover, we provide ample evidence for a novel functional link between p53 and caspase-dependent cell death as outlined in Figure 6. At this point, it is not sure whether this novel linkage is cell-type specific or more or less ubiquitous irrespective of cell contexts.

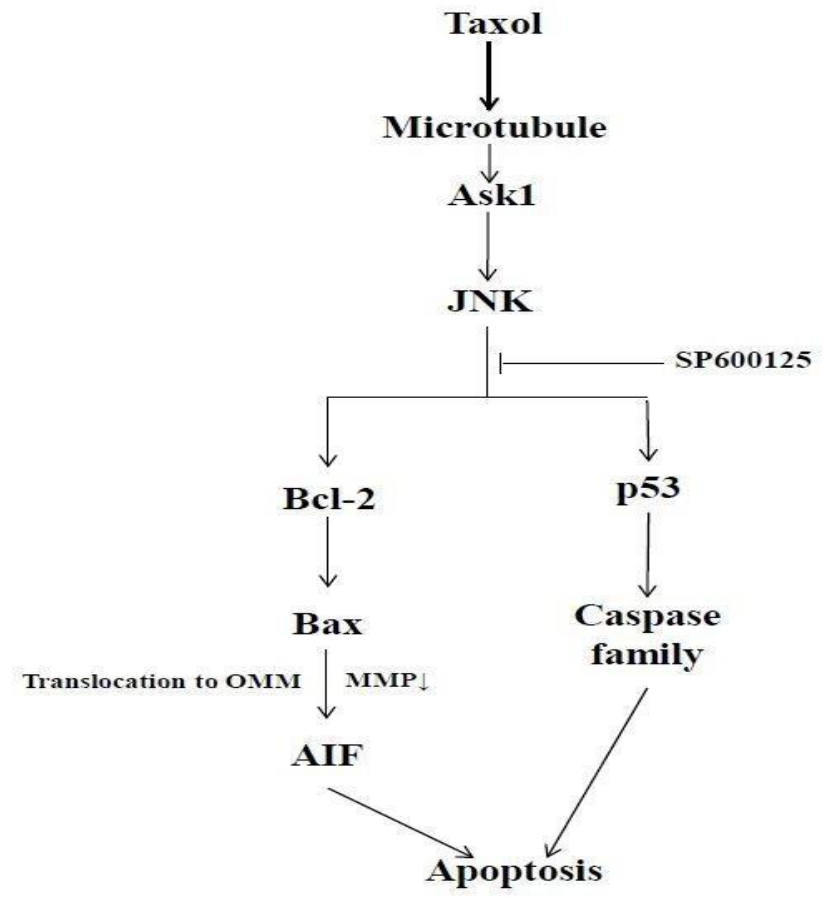

Figure 6: Summary of the apoptotic signaling triggered by taxol in SKOV3 cells. Upon taxol treatment, SKOV3 cells follow the caspaseindependent apoptotic signaling, leading to AIF release from the mitochondria, but in the presence of p53, the cells may gain access to, otherwise silent, the caspase-dependent signaling pathway. JNK is located upstream of both apoptotic signaling pathways and play a key role in leading to apoptotic cell death.

Of note, it is worth mentioning that a number of recent papers demonstrated evidence that supports that wild type SKOV3 cells executes taxol-introduced cell death in a caspase-3-dependent manner [51-53]. It is well documented that the activation of caspase 3, a main executor protease in apoptosis, is again under heavy influence of various upstream signals coming from both extrinsic (death ligand) and intrinsic (mitochondrial) pathways; some are positive while others are negative regulators depending on the physiological context. Therefore, it is not surprising that other studies support the apoptotic cell death in wild type SKOV3 cells after taxol treatment is executed in a caspase-3-dependent manner. The physiological context of wild type SKOV 3 cells could be various depending on, for instance, culture conditions, cell passage numbers (cell history), whether or not transfected with a foreign gene, and etc. What we saw in this study was a pair-wise comparison between wild type SKOV3 cells and P53transfected SKOV3 cells in terms of the emergence of cleaved form of caspase 3. And our results clearly saw a difference that the cleaved form of caspase 3 only came from P53-transfectants in response to taxol but negligible in wild type SKOV3 cells. Also supporting this argument, we have published similar results previously [36]. So, it is remained to be seen whether wild type SKOV3 cells recruit caspase 3 when they commit the taxol-introduced cell death.

In conclusion, our study suggests that the p53-mediated apoptosis may play a significant role in apoptotic cell death of many cancer cells, including ovarian cancer, in response to a variety of anticancer chemotherapeutics.
Deletion or mutation(s) of wild type p53 could lead to the elevation of the threshold for anticancer drugs or the attenuation of their efficacies against cancers due to the abrogation of the p53-mediated apoptosis. For this reason, the p53-mediated apoptosis deserves a more stringent investigation to gain further insight into a new strategy for promoting cancer cell death and leading to efficient cancer prevention.

\section{References}

1. Jordan MA, Toso RJ, Thrower D, Wilson L. Mechanism of mitotic block and inhibition of cell proliferation by taxol at low concentrations. Proc Natl Acad Sci U S A. 1993;90(20):9552-6.

2. Damia G, Broggini M. 2004. Cell cycle checkpoint proteins and cellular response to treatment by anticancer agents. Cell Cycle. 2004;3(1):46-50.

3. Suzuki A, Kawabata T, Kato M. Necessity of interleukin-1beta converting enzyme cascade in taxotere-initiated death signaling. Eur J Pharmacol. 1998:343(1):87-92.

4. Shtil AA, Mandlekar S, Yu R, Walter RJ, Hagen K, Tan TH, et al. Differential regulation of mitogen-activated protein kinases by microtubule-binding agents in human breast cancer cells. Oncogene. 1999;18(2):377-84.

5. Fan M, Du L, Stone AA, Gilbert KM, Chambers TC. Modulation of mitogen-activated protein kinases and phosphorylation of $\mathrm{Bcl}-2$ by vinblastine represent persistent forms of normal fluctuations at G2M1. Cancer Res. 2000;60(22):6403-7.

6. Davis RJ. Signal transduction by the JNK group of MAP kinases. Cell. 2000;103(2):239-52.

7. Mingo-Sion AM, Marietta PM, Koller E, Wolf DM, Van Den Berg CL. Inhibition of JNK reduces G2/M transit independent of p53, leading to endure duplication, decreased proliferation, and apoptosis in breast cancer cells. Oncogene. 2004;23(2):596-604.

8. Lei K, Nimnual A, Zong WX, Kennedy NJ, Flavell RA, Thompson $\mathrm{CB}$, et al. The Bax subfamily of Bcl2-related proteins is essential for apoptotic signal transduction by c-Jun $\mathrm{NH}(2)$-terminal kinase. Mol Cell Biol. 2002;22(13):4929-42.

9. Wang TH, Wang HS, Ichijo H, Giannakakou P, Foster JS, Fojo T, et al. Microtubule-interfering agents activate c-Jun N-terminal kinase/stress-activated protein kinase through both Ras and apoptosis signal-regulating kinase pathways. J Biol Chem. 1998;273(9):4928 36.

10. Zhang H, Shi X, Zhang QJ, Hampong M, Paddon H, Wahyuningsih $\mathrm{D}$, et al. Nocodazole-induced p53-dependent c-Jun N-terminal kinase activation reduces apoptosis in human colon carcinoma HCT116 cells. J Biol Chem. 2002;277(46):43648-58.

11. Wang XS, Diener K, Jannuzzi D, Trollinger D, Tan TH, Lichenstein $\mathrm{H}$, et al. Molecular cloning and characterization of a novel protein kinase with a catalytic domain homologous to mitogen-activated protein kinase kinase kinase. J Biol Chem. 1996; 271:31607-11.

12. Ichijo H, Nishida E, Irie K, ten Dijke P, Saitoh M, Moriguchi T, et al. Induction of apoptosis by ASK1, a mammalian MAPKKK that activates SAPK/JNK and p38 signaling pathways. Science. 1997;275(5296):90-4

13. Chen Z, Seimiya H, Naito M, Mashima T, Kizaki A, Dan S, et al. ASK1 mediates apoptotic cell death induced by genotoxic stress. Oncogene. 1999;18(1):173-80.

14. Kanamoto T, Mota M, Takeda K, Rubin LL, Miyazono K, Ichijo H, et al. Role of apoptosis signal-regulating kinase in regulation of the cJun N-terminal kinase pathway and apoptosis in sympathetic neurons. Mol Cell Biol. 2000;20(1):196-204.

15. Saitoh M, Nishitoh H, Fujii M, Takeda K, Tobiume K, Sawada Y, et al. Mammalian thioredoxin is a direct inhibitor of apoptosis signalregulating kinase (ASK) 1. EMBO J. 1998;17(9):2596-606.

16. Yamamoto K, Ichijo H, Korsmeyer SJ. BCL-2 is phosphorylated and inactivated by an ASK1/Jun N-terminal protein kinase pathway normally activated at G(2)/M. Mol Cell Biol. 1999;19(12):8469-78.

17. Matsukawa J, Matsuzawa A, Takeda K, Ichijo H. The ASK1-MAP kinase cascades in mammalian stress response. $\mathrm{J}$ Biochem. 2004;136(3):261-5. 
18. Meek DW. Multisite phosphorylation and the integration of stress signals at p53. Cell Signal. 1998;10(3):159-66.

19. Ryan KM, Phillips AC, Vousden KH. Regulation and function of the p53 tumor suppressor protein. Curr Opin Cell Biol. 2001;13(3):332-7.

20. Miyashita T, Reed JC. Tumor suppressor p53 is a direct transcriptional activator of the human bax gene. Cell. 1995;80(2):293-9.

21. Sablina AA, Chumakov PM, Levine AJ, Kopninp BP. p53 activation in response to microtubule disruption is mediated by integrin-Erk signaling. Oncogene. 2001;20(8):899-909.

22. Stewart ZA, Tang LJ, Pietenpol JA. Increased p53 phosphorylation after microtubule disruption is mediated in a microtubule inhibitor- and cell-specific manner. Oncogene. 2001;20(1):113-24.

23. Sionov RV, Haupt Y. The cellular response to p53: the decision between life and death. Oncogene. 1999;18(45):6145-57.

24. Cossarizza A, Baccarani-Contri M, Kalashnikova G, Franceschi C. A new method for the cytofluometric analysis of mitochondrial membrane potential using the $\mathrm{J}$-aggregate forming lipophilic cation 5,5',6,6'-tetrachloro-1,1',3,3'tetraethylbenzimidazolcarbocyanine iodide (JC-1). Biochem Biophys Res Commun. 1993;197(1):40-5.

25. Potapova O, Haghighi A, Bost F, Liu C, Birrer MJ, Gjerset R, et al. The Jun kinase/stress-activated protein kinase pathway functions to regulate DNA repair and inhibition of the pathway sensitizes tumor cells to cisplatin. J Biol Chem. 1997;272(22):14041-4.

26. Yagi H, Yotsumoto F, Sonoda K, Kuroki M, Mekada E, Miyamoto S. Synergistic anti-tumor effect of paclitaxel with CRM197, an inhibitor of HB-EGF, in ovarian cancer. Int $\mathbf{J}$ Cancer. 2009;124(6):1429-39. doi: 10.1002/ijc.24031.

27. Kharbanda S, Saxena S, Yoshida K, Pandey P, Kaneki M, Wang $\mathrm{Q}$, et al. Translocation of SAPK/JNK to mitochondria and interaction with $\mathrm{Bcl}-\mathrm{x}(\mathrm{L})$ in response to DNA damage. $\mathrm{J}$ Biol Chem. 2000;275(1):322-7.

28. Ito Y, Mishra NC, Yoshida K, Kharbanda S, Saxena S, Kufe D. Mitochondrial targeting of JNK/SAPK in the phorbol ester response of myeloid leukemia cells. Cell Death Differ. 2001;8(8):794-800.

29. Lee S-H, Park S-W, Pyo C-W, Yoo NK, Kim J, Choi SY. Requirement of the JNK-associated Bcl-2 pathway for human lactoferrin-induced apoptosis in the Jurkat leukemia $\mathrm{T}$ cell line. Biochimie. 2009;91(1):102-8. doi: 10.1016/j.biochi.2008.05.004.

30. Gross A, Jockel J, Wei MC, Korsmeyer SJ. Enforced dimerization of BAX results in its translocation, mitochondrial dysfunction and apoptosis. EMBO J. 1998;17(14):3878-85.

31. Hsu YT, Wolter KG, Youle RJ. Cytosol-to-membrane redistribution of $\mathrm{Bax}$ and $\mathrm{Bcl}-\mathrm{X}(\mathrm{L})$ during apoptosis. Proc Natl Acad Sci U S A. 1997;94(8):3668-72.

32. Er E, Oliver L, Cartron PF, Juin P, Manon S, Vallette FM. Mitochondria as the target of the pro-apoptotic protein Bax. Biochim Biophys Acta. 2006;1757(9-10):1301-11.

33. Nechushtan A, Smith CL, Hsu YT, Youle RJ. Conformation of the Bax C-terminus regulates subcellular location and cell death. EMBO J. 1999;18(9):2330-41.

34. Priault M, Camougrand N, Chaudhuri B, Manon S. Role of the C-terminal domain of Bax and Bcl-XL in their localization and function in yeast cells. FEBS Lett. 1999;443(2):225-8.

35. Goping IS, Gross A, Lavoie JN, Nguyen M, Jemmerson R, Roth $\mathrm{K}$, et al. Regulated targeting of BAX to mitochondria. J Cell Biol. 1998;143(1):207-15.
Ahn HJ, Kim YS, Kim JU, Han SM, Shin JW, Yang HO. Mechanism of taxol-induced apoptosis in human SKOV3 ovarian carcinoma cells. J Cell Biochem. 2004;91(5):1043-52.

37. Corney DC, Flesken-Nikitin A, Choi J, Nikitin AY. Role of p53 and $\mathrm{Rb}$ in ovarian cancer. Adv Exp Med Biol. 2008;622:99-117. doi: 10.1007/978-0-387-68969-2_9.

38. Bressenot A, Marchal S, Bezdetnaya L, Garrier J, Guillemin F, Plénat F. Assessment of apoptosis by immunohistochemistry to active caspase-3, active caspase-7, or cleaved PARP in monolayer cells and spheroid and subcutaneous xenografts of human carcinoma. J Histochem Cytochem. 2009;57(4):289-300. doi: 10.1369/jhc.2008 .952044 .

39. Kyriakis JM, Avruch J. p54 microtubule-associated protein 2 kinase. A novel serine/threonine protein kinase regulated by phosphorylation and stimulated by poly-L-lysine. J Biol Chem. 1990; 265:17355-63.

40. Adler V, Polotskaya A, Wagner F, Kraft AS. Affinity-purified c-Jun amino-terminal protein kinase requires serine/threonine phosphorylation for activity. J Biol Chem. 1992;267(24):17001-5.

41. Hibi M, Lin A, Smeal T, Minden A, Karin M. Identification of an oncoprotein-and UV-responsive protein kinase that binds and potentiates the c-Jun activation domain. Genes Dev. 1993;7(11):2135-48.

42. Pulverer BJ, Kyriakis JM, Avruch J, Nikolakaki E, Woodgett JR. Phosphorylation of c-jun mediated by MAP kinases. Nature. 1991;353(6345):670-4.

43. Ip YT, Davis RJ. Signal transduction by the c-Jun N-terminal kinase (JNK)--from inflammation to development. Curr Opin Cell Biol. 1998;10(2):205-19.

44. Ichijo H, Nishida E, Irie K, ten Dijke P, Saitoh M, Moriguchi T, et al. Induction of apoptosis by ASK1, a mammalian MAPKKK that activates SAPK/JNK and p38 signaling pathways. Science. 1997;275(5296):90-4.

45. Hatai T, Matsuzawa A, Inoshita S, Mochida Y, Kuroda T, Sakamaki $\mathrm{K}$, et al. Execution of apoptosis signal-regulating kinase 1(ASK1)induced apoptosis by the mitochondria-dependent caspase activation. J Biol Chem. 2000;275(34):26576-81.

46. Ito M, Yoshioka K, Akechi M, Yamashita S, Takamatsu N, Sugiyama K, et al. JSAP1, a novel jun N-terminal protein kinase (JNK)-binding protein that functions as a Scaffold factor in the JNK signaling pathway. Mol Cell Biol. 1999;19(11):7539-48.

47. Xia Z, Dickens M, Raingeaud J, Davis RJ, Greenberg ME. Opposing effects of ERK and JNK-p38 MAP kinases on apoptosis. Science. 1995;270(5240):1326-31.

48. Ahn HJ, Koketsu M, Yang EM, Kim YM, Ishihara H, Yang HO. 2(4-Methylphenyl)-1,3-selenazol-4-one induces apoptosis by different mechanisms in SKOV3 and HL 60 cells. J Cell Biochem. 2006;99(3):807-15.

49. Fuchs SY, Adler V, Pincus MR, Ronai Z. MEKK1/JNK signaling stabilizes and activates p53. Proc Natl Acad Sci U S A. 1998;95(18): 10541-6.

50. Chen YR, Tan TH. The c-Jun N-terminal kinase pathway and apoptotic signaling. Int J Oncol. 2000;16(4):651-62.

51. Huang S, Bijangi-Vishehsaraei K, Saadatzadeh MR, Safa AR. Human GM3 synthase attenuates taxol-triggered apoptosis associated with downregulation of caspase- 3 in ovarian cancer cells. J Cancer Ther. 2012;3(5):504-510.

52. Wu YJ, Neuwelt AJ, Muldoon LL, Neuwelt EA. Acetaminophen enhances cisplatin- and paclitaxel-mediated cytotoxicity to SKOV3 human ovarian carcinoma. Anticancer Res. 2013;33(6):2391-400.

53. Wang AC, Ma YB, Wu FX, Ma ZF, Liu NF, Gao R, et al. TLR4 induces tumor growth and inhibits paclitaxel activity in MyD88positive human ovarian carcinoma in vitro. Oncol Lett. 2014;7(3):871-877. 